\title{
PSYCHIATRIC COMORBIDITIES IN PATIENTS WITH SUBSTANCE USE DISORDERS COMING FOR DE-ADDICTION TREATMENT IN A TERTIARY CARE HOSPITAL OF WESTERN INDIA
}

\author{
Atul Agrawal1, Jaiprakash Agrawal2
}

${ }^{1}$ Associate Professor and Head, Department of Psychiatry, G. R. Medical College, Gwalior, Madhya Pradesh, India.

${ }^{2}$ Associate Professor, Department of Psychiatry, Gandhi Medical College, Bhopal, Madhya Pradesh, India.

ABSTRACT
BACKGROUND
Psychiatric comorbidities are common in patients with substance use disorder \& they tend to complicate the management, course
\& prognosis of both disorders. So, this study was conducted in the M.B.S. Hospital of Govt. Medical College, Kota, to know the
psychiatric comorbidities in patients with substance use disorder, coming for the de-addiction treatment in a tertiary care hospital
of western India.

\section{MATERIALS \& METHODS}

This is a case control study. 50 patients of substance use disorder were compared with the 50 age \& sex matched controls \& assessed by the especially designed semistructured performa, General Health Questionnaire \& Indian Psychiatric Interview Schedule. Convenience sampling method was used for taking the sample. Data so collected was displayed in the form of various tables. Chi square test was used to test the significance.

\section{RESULTS}

$54 \%$ patients with substance use disorder were found to have co-morbid psychiatric diagnoses in comparison to $12 \%$ psychiatric morbidity in control group. In psychiatric co-morbidities, depressive disorder was the commonest diagnosis followed by anxiety disorder, personality disorder, bipolar disorder \& schizophrenia spectrum disorders.

\section{CONCLUSION}

Effective management of psychiatric comorbidities is necessary for improvement in substance related behavioural \& psychosocial outcomes. So the regular screening \& management of psychiatric comorbidities should be the essential routine practice in deaddiction clinics \& mental health care settings.

\section{KEY WORDS}

Dependence, Comorbidities, Deaddiction.

HOW TO CITE THIS ARTICLE: Agrawal A, Agrawal J. Psychiatric comorbidities in patients with substance use disorders coming for deaddiction treatment in a tertiary care hospital of Western India. J. Evolution Med. Dent. Sci. 2018;7(51):5416-5419, DOI: $10.14260 /$ jemds/2018/1199

\section{BACKGROUND}

Substance abuse is emerging as a major challenge to public health throughout the world. Substance use has increased rapidly in recent years due to increased drug trafficking \& easy availability. It also has a great social relevance as it affects the youth in manifolds \& thus impairing the vital work force of the society. Substance use becomes more complicated when it is co-morbid with psychiatric illnesses.

Psychiatric morbidity in individuals with substance use disorders is substantial \& sometimes "dual diagnosis" term is used synonymously with the comorbidity.[1] It is of critical importance for several reasons because psychiatric comorbidity has been found to have a negative impact on the course, treatment outcome and prognosis of both disorders.

'Financial or Other Competing Interest': None.

Submission 25-10-2018, Peer Review 04-12-2018,

Acceptance 10-12-2018, Published 17-12-2018.

Corresponding Author:

Dr. Jaiprakash Agrawal,

Associate Professor,

Department of Psychiatry,

Gandhi Medical College,

Bhopal, Madhya Pradesh,

India.

E-mail: jaiprakash_agrawal@yahoo.com

DOI: $10.14260 /$ jemds/2018/1199
In the study conducted by the National Institute of Mental Health Epidemiologic Catchment Area Program study, 20, 291 persons were interviewed for the assessment of Psychiatric co-morbidity with alcohol and other drug abuse. Psychiatric comorbidity was found in 37\% persons with alcohol disorder \& 53\% persons with other non-alcohol drug disorder.[2] In various studies, significant psychiatric morbidity was found in substance abusers where mood \& anxiety disorder were the commonest diagnosis followed by other psychiatric disorders like personality disorders \& psychotic disorders. In mental health settings \& de-addiction clinics these co-morbidities are often undetected, misdiagnosed \& inadequately treated. ${ }^{[3]}$ As such recognition of the overlap of psychiatric and substance use disorders is an important issue for appropriate, safe and adequate treatment.

Research points out that effective management of both substance use disorder and psychiatric morbidity leads to better outcome in behavioural \& psychosocial dimension. [4] Higher psychiatric morbidity has been found in different parts of the world in various studies, since local, social \& cultural factors may affect psychiatric comorbidity hence this hospital-based study is planned to investigate the psychiatric morbidity in substance abusers attending tertiary care hospital in Hadoti region of Rajasthan. 


\section{Aim of the Study}

To study the psychiatric comorbidity in substance abusers.

\section{MATERIALS \& METHODS}

\section{Study Design}

Case Control Study.

\section{Sample of Study}

This study was conducted in the OPD and Indoor of Department of Psychiatry, M. B. S. Hospital, attached to Govt. Medical College, Kota (Raj.). Before starting the study approval of the Principal \& Controller Medical College \& ethical committee was taken.

50 consecutive cases fulfilling inclusion criteria who gave informed consent were taken for the study. The sample size of 50 substance users in study group and 50 age and sex matched controls in control group were taken for convenience. 50 substance user patients attending psychiatry OPD and admitted in De-addiction ward under Department of Psychiatry, M.B.S. Hospital, Kota, who fulfilled the inclusion criteria constituted the sample of study (Study group). These substance abuser cases were compared with 50 age \& sex matched controls preferably relatives or family members of substance abusers, who were not abusing any substance in the present or in the past except tobacco (Control group). Both groups were given assurance that information disclosed by them will be kept confidential and will be used for research purpose only.

\section{Sampling Technique}

\section{Convenience sampling was used taking samples.}

This is a non-probability sampling technique where subjects were selected because of their convenient accessibility and proximity to the researcher, due to time constraint.

\section{Inclusion Criteria}

1. Persons in the age range from 18-60 years.

2. Persons who gave informed consent.

3. Substance abusers who fulfilled the criteria of Substance use disorder according to ICD-10 \& confirmed by the consultant psychiatrist. [5]

\section{Exclusion Criteria}

Persons suffering from any serious medical including organic neurological disorders and surgical illness.

\section{Tools of Study}

1. Especially Designed Semi-structured Proforma comprising relevant demographic data and clinical history was used for the study.

2. Goldberg's Health Questionnaire-12: It is a selfadministered 12-item questionnaire commonly used as a screening tool for detecting psychological problems. [6]

3. Indian Psychiatry Interview Schedule (I. P. I. S.)- This is a structured instrument for the use in investigating psychopathology in an Indian context, developed and improved through a numbers of pilot studies conducted at National Institute of Mental Health and Neurosciences (N.I.M.H.A.N.S.), Bangalore (Kapur et al, 1974).[7]
All the subjects (Substance abusers as well as controls) who fulfilled the inclusion criteria were evaluated in detail using especially designed proforma and above-mentioned tools. Data so collected was displayed in the form of various tables. Chi square test was used to test the significance \& $\mathrm{P}$ value for statistical significance was taken at 0.05 . Conclusions were drawn following the statistical analysis \& the implications of the findings were discussed.

\section{RESULTS}

Data obtained in the study are depicted in following tables.

\begin{tabular}{|c|c|c|c|}
\hline Age (yrs.) & $\begin{array}{l}\text { Study } \\
\text { Group } \\
(\mathrm{N}=50)\end{array}$ & $\begin{array}{c}\text { Control Group } \\
(\mathrm{N}=50)\end{array}$ & \\
\hline$<20$ & $2(4 \%)$ & $1(2 \%)$ & \multirow{6}{*}{$\begin{array}{c}\mathrm{X}^{2}=2.957 \\
\mathrm{df}=5 \\
\mathrm{p}=0.7065\end{array}$} \\
\hline $21-25$ & $9(18 \%)$ & $11(22 \%)$ & \\
\hline $26-30$ & $13(26 \%)$ & $18(36 \%)$ & \\
\hline $31-35$ & $18(36 \%)$ & $16(32 \%)$ & \\
\hline $36-40$ & $5(10 \%)$ & $3(6 \%)$ & \\
\hline$>40$ & $3(6 \%)$ & $1(2 \%)$ & \\
\hline \multicolumn{3}{|c|}{ Sex } & \multirow{3}{*}{$\begin{array}{l}P \text { value not } \\
\text { significant }\end{array}$} \\
\hline Male & $50(100 \%)$ & $50(100 \%)$ & \\
\hline Female & 00 & 00 & \\
\hline \multicolumn{3}{|c|}{ Occupation } & \multirow{4}{*}{$\begin{array}{c}\mathrm{X}^{2}=9.462 \\
\mathrm{df}=2 \\
\mathrm{p}=0.0088\end{array}$} \\
\hline Never Employed & $7(14 \%)$ & $4(8 \%)$ & \\
\hline $\begin{array}{c}\text { Presently } \\
\text { Unemployed }\end{array}$ & $16(32 \%)$ & $5(10 \%)$ & \\
\hline Employed & $27(54 \%)$ & $41(82 \%)$ & \\
\hline \multicolumn{3}{|c|}{ Education } & \multirow{7}{*}{$\begin{array}{c}\mathrm{X}^{2}=11.301, \\
\mathrm{df}=5, \\
\mathrm{p}=0.0457\end{array}$} \\
\hline Illiterate & $5(10 \%)$ & $3(6 \%)$ & \\
\hline Primary & $18(36 \%)$ & $7(14 \%)$ & \\
\hline Middle & $12(24 \%)$ & $10(20 \%)$ & \\
\hline Secondary & $8(16 \%)$ & $14(28 \%)$ & \\
\hline Sr. Secondary & $4(8 \%)$ & $12(24 \%)$ & \\
\hline Graduate \& Above & $3(6 \%)$ & $4(8 \%)$ & \\
\hline \multicolumn{3}{|c|}{ Table 1. Demographic Data } & \\
\hline
\end{tabular}

\begin{tabular}{|c|c|}
\hline Chief Substance & Study Group (N=50) \\
\hline Opioids & $31(62 \%)$ \\
\hline Alcohol & $12(24 \%)$ \\
\hline Multi-Substance & $4(8 \%)$ \\
\hline Cannabis & $2(4 \%)$ \\
\hline Benzodiazepines & $1(2 \%)$ \\
\hline $\begin{array}{r}\text { ble 2. Distribution } \\
\text { Chief }\end{array}$ & $\begin{array}{l}\text { nce Abusers according to } \\
\text { of Abuse }\end{array}$ \\
\hline
\end{tabular}

\begin{tabular}{|c|c|c|}
\hline Psychiatric Illness & $\begin{array}{c}\text { Study Group } \\
\text { (N=50) }\end{array}$ & $\begin{array}{c}\text { Control Group } \\
\text { (N=50) }\end{array}$ \\
\hline No Illness & $23(46 \%)$ & $44(88 \%)$ \\
\hline Depression & $14(28 \%)$ & $4(8 \%)$ \\
\hline $\begin{array}{c}\text { Anxiety Spectrum Disorder } \\
\text { (Generalized Anxiety } \\
\text { Disorder, Panic Attacks etc.) }\end{array}$ & $5(10 \%)$ & $2(4 \%)$ \\
\hline Personality Disorder & $4(8 \%)$ & $0(0 \%)$ \\
\hline Bipolar Affective Disorder & $2(4 \%)$ & $0(0 \%)$ \\
\hline $\begin{array}{c}\text { Schizophrenia Spectrum } \\
\text { Disorder (Schizophrenia, } \\
\text { Delusional Disorder etc.) }\end{array}$ & $2(4 \%)$ & $0(0 \%)$ \\
\hline \multicolumn{2}{|c|}{ (X) ${ }^{2}=19.399$, d/f = 5, p=0.0016, p<.001), Highly significant } \\
\hline \multicolumn{2}{|c|}{ Table 3. Psychiatric Morbidity } \\
\hline
\end{tabular}




\begin{tabular}{|c|c|c|c|}
\hline $\begin{array}{c}\text { Attempted } \\
\text { Suicides } \\
\end{array}$ & $\begin{array}{l}\text { Study } \\
\text { Group }\end{array}$ & $\begin{array}{c}\text { Control } \\
\text { Group }\end{array}$ & Significance \\
\hline Present & $08(16 \%)$ & $01(2 \%)$ & $\mathrm{X}^{2}=5.98, \mathrm{df}=1$, \\
\hline Absent & $42(84 \%)$ & $49(98 \%)$ & \\
\hline \multicolumn{3}{|c|}{ Suicidal Ideation } & \multirow{3}{*}{$\begin{array}{c}\mathrm{X}^{2}=36.97, \mathrm{df}=1, \\
\mathrm{p}<.05\end{array}$} \\
\hline Present & $32(64 \%)$ & $03(6 \%)$ & \\
\hline Absent & $18(36 \%)$ & $47(94 \%)$ & \\
\hline
\end{tabular}

\section{DISCUSSION}

In our study all the patients were males \& most of them belong to the age group of 21 to 35 years. Chief substance of abuse were opioids (64\%) followed by alcohol (24\%), multisubstance $(8 \%) \&$ cannabis $(4 \%)$. Table 3 presents the distribution according to the Psychiatric morbidity in substance users and controls. It is evident from the table that psychiatric morbidity was significantly more in substance abusers (54\%) as compared to controls (12\%). In various psychiatric diagnoses, depression was the most common diagnosis in substance abusers $(28 \%)$ followed by anxiety disorder $(10 \%)$, personality disorder $(8 \%)$, bipolar affective disorder and schizophrenia spectrum disorder ( $4 \%$ each). In control group 8\% suffered from depressive disorder and $4 \%$ suffered from anxiety disorder. No control was found to be suffering from personality disorder, bipolar affective disorder or schizophrenia spectrum disorder. The statistical difference between both the groups was found to be significant. The findings of our study match with various previous studies done by Subodh B.N.et al[8], Ahmed B. et al. (2001),[9] Middha P.K. et al. (2001),[10] Rui C. et al. (2000),[11] Goeb et al. (2000),[12] ECA study (1990) [2] and Bronner R.K. (1997)[13] in which they found higher psychiatric morbidity in substance abusers.

Dara A. et al. (2005) ${ }^{[14]}$ assessed the rates of concurrent psychiatric symptoms among 326 patients entering deaddiction treatment and found that majority of the patients (63\%) had significant psychiatric symptoms with $32 \%$ presenting with combined depressive and anxiety symptoms. Rui C. et al. (2000) found a higher prevalence of depressive disorders in drug addicts irrespective of the type and duration of substance abuse \& a significant correlation between depression and severity of drug addiction. Bronner R.K. et al. (1997)[13] found psychiatric morbidity in $47 \%$ of substance abusers and concluded that psychiatric disorder was associated with a more severe substance use disorder.

In Opioid dependent population Kessler et al (1996)[15] found about 50\% comorbidity while Dake et al (1994)[16] and Limbeek et al (1992)[17] reported $60 \%$ and $85 \%$ psychiatric co- morbidity in their respective studies.

Blachut $\mathrm{M}$ et al (2013) ${ }^{[18]}$ found $30.5 \%$ dual diagnosis in substance abusers and mood disorder was the most frequent diagnosis.

In contrast to above results, few studies reported psychotic disorder as most common co-morbidities followed by depressive disorders. Gania et al (2017)[19] found psychotic disorders 34\%, depressive disorders 16\% \& 11.5\% PTSD as common diagnoses in substance users while Balhara et al (2017)[20] found Psychotic disorders in 38.7\% \& depressive disorders in $27.5 \%$ as comorbidities in patients with substance related disorders but most of the studies reported depressive disorders and anxiety disorders as the most common comorbidities in substance abusers. This difference may be due to sampling method, selection criteria and type of substance used by the patients seeking the treatment for de-addiction therapy.

Subodh B N et al (2017) studied dual diagnosis in patients visited in the de-addiction centre of PGIMER Chandigarh \& reported $32.4 \%$ dual diagnosis in clinical sample in which mood disorders $(12.3 \%)$ was the commonest diagnosis followed by anxiety disorders (11.2\%) \& psychotic disorders (5\%). [8]

Debashish et al (2012) analysed the records of 5, 116 substance users registered in deaddiction clinic over the span of 11 years \& found psychiatric comorbidities in $13.2 \%$ patients. In comorbidities mood disorder (42.2\%) was the most common diagnosis followed by psychotic disorders $(27.5 \%)$, anxiety disorders $(16.7 \%)$, personality disorders (10.1\%), organic disorders ( $4.5 \%)$, and others (4.6\%).[21]

In current study suicidal attempts \& suicidal ideation were found in $16 \%$ \& $64 \%$ substance abusers respectively while in control group we found suicidal attempts in $2 \%$ cases \& suicidal ideations in $6 \%$ cases. The difference was found to be statistically significant. Kessler et.al (1999) found in National comorbidity survey that substance abusers had 6 times more history of suicidal attempt than the person without a substance use disorder.[22]

Maloney E et al (2007) assessed 726 opioid dependent cases \& found suicidal thoughts in $66 \%$ \& suicidal attempts in $19 \%$ cases.[23] In various studies on drug addicts, drug addiction has been found to increase the chances of suicide attempts and current suicidal ideation in individuals. [24,25]

Substance abusers with history of past suicide attempt have increased risk for suicidal behaviours in future also. [26]

Depression is the commonest psychiatric illness associated with the suicide behaviours in general population as well as in substance abusers.[24,27] Increased suicidal behaviours also indicates higher comorbidity of depressive disorders with substance use disorders.[28]

\section{CONCLUSION}

Substance abusers had significant psychiatric morbidity. Depressive \& anxiety disorders were the most common diagnoses. In routine clinical practice, these comorbidities go undetected in patients coming for de-addiction treatment. Timely detection \& management of these psychiatric comorbidities are vital for better management of substance related disorders \& for preventing their relapse also. So, the substance users coming for the de-addiction treatment should be routinely screened for psychiatric co-morbidity.

\section{Limitations of the Study}

This was a hospital-based study and size of the sample was small and there was possibility of sampling bias, hence the findings of this study cannot be generalized. Therefore, a community based longitudinal, prospective study with larger sample may be carried out to explore psychiatric morbidity of patients with substance use disorder.

\section{REFERENCES}

[1] Basu D, Gupta N. Management of "dual diagnosis" patients: consensus, controversies and considerations. Indian J Psychiatry 2000;42(1):34-47.

[2] Regier DA, Farmer ME, Rae DS, et al. Comorbidity of mental disorders with alcohol and other drug abuse results from the Epidemiologic Catchment Area (ECA) Study. JAMA 1990;264(19):2511-8. 
[3] Morojele NK, Saban A, Seedat S. Clinical presentations and diagnostic issues in dual diagnosis disorders. Curr Opin Psychiatry 2012;25(3):181-6.

[4] Morisano D, Babor TF, Robaina KA. Co-occurrence of substance use disorders with other psychiatric disorders: implications for treatment services. Nordic Studies on Alcohol and Drugs, First Published April 12, 2017.

[5] The ICD-10: classification of mental health and Behavioral Disorders. Diagnostic Criteria for research, Geneva, World Health Organisation, 1993.

[6] Goldberg DP. The General Health Questionnaire (GHQ): Companion to Psychiatric studies. Oxford University Press 1972: p. 172-3.

[7] Kapur RL, Kapur M, Carstairs GM. Indian Psychiatric Interview Schedule (IPIS). Social Psychiatry 1974;9:61-69.

[8] Subodh BN, Hazari N, Elwadhi D, et al. Prevalence of dual diagnosis among clinic attending patients in a deaddiction centre of a tertiary care hospital. Asian Journal of Psychiatry 2017;25:169-74.

[9] Ahmad B, Mufti KA, Farooq S. Psychiatric comorbidity in substance abuse (opioids). Journal of Pakistan Medical Association 2001;51(5):183-6.

[10] Midha PK, Kanwal K, Batra L. A study of comorbidity in patients abusing substance. Journal of Mental Health and Human Behavior 2001;6:137-45.

[11] Rui C, Rui R, Elisabete R, et al. Depression and the severity of substance abuse. Psychopathology (International Journal of Descriptive and Experimental Psychopathology, Phenomenology and Psychiatric Diagnosis) 2000;33(3).

[12] Goeb, JL, Coste J, Bigot T, et al. Prospective study of favorable factors in follow up study of drug addicted patients-apropos of 257 patients of the Cassini center in Paris. Encephale 2000;26(6):11-20.

[13] Brooner RK, King VL, Kidorf M, et al. Psychiatric and substance use comorbidity among treatment seeking opioid abusers. Archives of General Psychiatry 1997;54(1):71-80.

[14] Charney DA, Palacios-Boix J, Negrete JC, et al. Association between concurrent depression and anxiety and six-month outcome of addiction treatment. Psychiatry Survey 2005;56(8):927-33.

[15] Kessler RC, Nelson CB, McGonagle KA, et al. The epidemiology of co-occuring addictive and mental disorders: implications for prevention and service utilization. Am J Orthopsychiatry 1996;66(1):17-31.
[16] Dake S, Hall W, Swift W. Prevalence, symptoms and correlates of antisocial personality disorders among methadone maintenance clients. Drug Alcohol Depend 1994;34(3):253-7.

[17] Von Limbeek J, Wouters L, Kaplan CD, et al. Prevalence of Psychopathology in drug-addicted Dutch. J Subst Abuse Treat 1992;9(1):43-52.

[18] Błachut M, Badura-Brzoza K, Jarzab M, et al. Dual diagnosis in psychoactive substance abusing or dependent persons. Psychiatr Pol 2013;47(2):335-52.

[19] Gania AM, Margoob MA, Shah HU, et al. Psychiatric comorbidity in patients with substance use disorder: a hospital-based study. Indian J Soc Psychiatry 2017;33(1):63-6.

[20] Balhara YPS, Sarkar S, Bera SC, et al. Who seeks treatment for dual disorders? Observations from a dual disorder clinic at the National Drug Dependence Treatment Centre in India over a 12 year period. Int J High Risk Behav Addict 2017;6(1):e32501.

[21] Basu D, Sarkar S, Mattoo SK. Psychiatric comorbidity in patients with substance use disorders attending an addiction treatment center in india over 11 years: case for a specialized "dual diagnosis clinic". Journal of Dual Diagnosis 2012;9(1):23-9.

[22] Kessler RC, Borges G, Walters EE. Prevalence of and risk factors for lifetime suicide attempts in the National Comorbidity Survey. Arch Gen Psychiatry 1999;56(7):617-26.

[23] Maloney E, Degenhardt L, Darke S, et al. Suicidal behaviour and associated risk factors among opioiddependent individuals: a case-control study. Addiction 2007;102(12):1933-41.

[24] Ilgen MA, Burnette ML, Conner KR, et al. The association between violence and lifetime suicidal thoughts and behaviors in individuals treated for substance use disorders. Addict Behav 2010;35(2):111-5.

[25] Roy A. Characteristics of cocaine dependent patients who attempt suicide. Arch Suicide Res 2009;13(1):4651.

[26] Ilgen MA, Harris AH, Moos RH, et al. Predictors of a suicide attempt one year after entry into substance use disorder treatment. Alcohol Clin Exp Res 2007;31(4):635-42.

[27] Harris EC, Barraclough B. Suicide as an outcome for mental disorders. A meta-analysis. Br J Psychiatry 1997;170(3):205-28.

[28] Conner KR, Pinquart M, Gamble SA. Meta-analysis of depression and substance use among individuals with alcohol use disorders. J Subst Abuse Treat 2009;37(2):127-37. 